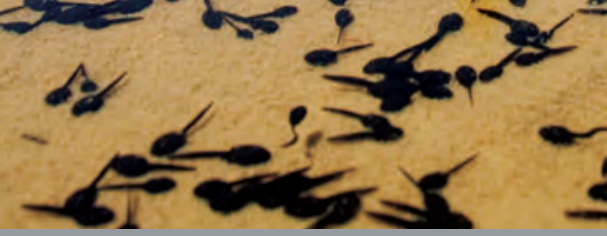

\title{
The State of Amphibians in the United States
}

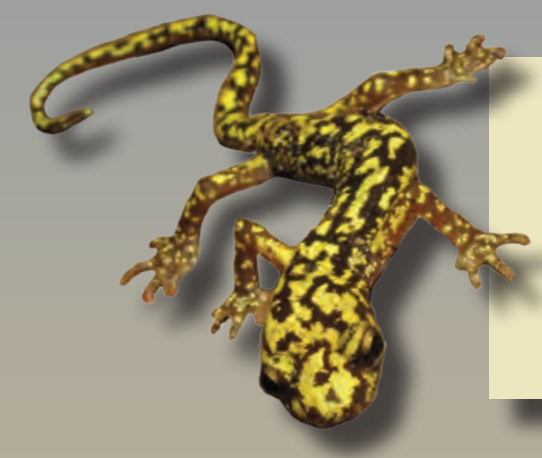

\section{Are Amphibians Really Declining?}

Clear evidence of major declines of amphibians in the United States and around the world has been established. The estimated rate of worldwide amphibian extinction since 1980 is thought to be 105 times higher than the background rate (McCallum, 2007). These declines threaten the extinction of 30 percent of the world's approximately 7,000 amphibian species (Stuart and others, 2004). This constitutes the greatest extinction event since the "Pleistocene extinctions" 10,000 years ago (Wake and Vredenburg, 2008).

The number of extinctions in the United States is not as extreme as in other parts of the world, but serious declines have been documented (for example, Mountain Yellow-legged Frog [Drost and Fellers, 1996]; Yosemite Toad [Sherman and Morton, 1993]; Boreal Toad [Corn and others, 1989; Muths and others 2003]; and Mississippi Gopher Frog [Richter and others, 2003]). Every ranid frog species in the western United States is on a list of concern. To date, the most comprehensive source of information on declines for amphibians in the United States is a species by species assessment summarized by Bradford (2005) that suggests about 42 percent of species are threatened or declining. A similar approach used by Stuart and others (2004) to classify the status of amphibians globally, suggests that 21 percent of species in the United States are declining.

\section{Estimates of amphibian declines.}

\begin{tabular}{cccc}
\hline $\begin{array}{c}\text { Amphibian } \\
\text { species } \\
\text { threatened or } \\
\text { declining } \\
\text { (percent) }\end{array}$ & Method & $\begin{array}{c}\text { Species and places } \\
\text { considered }\end{array}$ & Source \\
\hline 42 & Expert opinion & United States (all) & Bradford (2005) \\
21 & Expert opinion & United States (all) & $\begin{array}{c}\text { Stuart and others } \\
\text { (2004) }\end{array}$ \\
${ }^{1} 61$ & $\begin{array}{r}\text { Quantitative } \\
\text { monitoring }\end{array}$ & $\begin{array}{c}\text { United States (non- } \\
\text { random subset) }\end{array}$ & $\begin{array}{c}\text { ARMI monitoring } \\
\text { data }\end{array}$ \\
\hline
\end{tabular}

${ }^{1}$ Percentage of cases where any level of decline occurred from 2002 to 2011. Some of these declines likely are part of natural fluctuations.

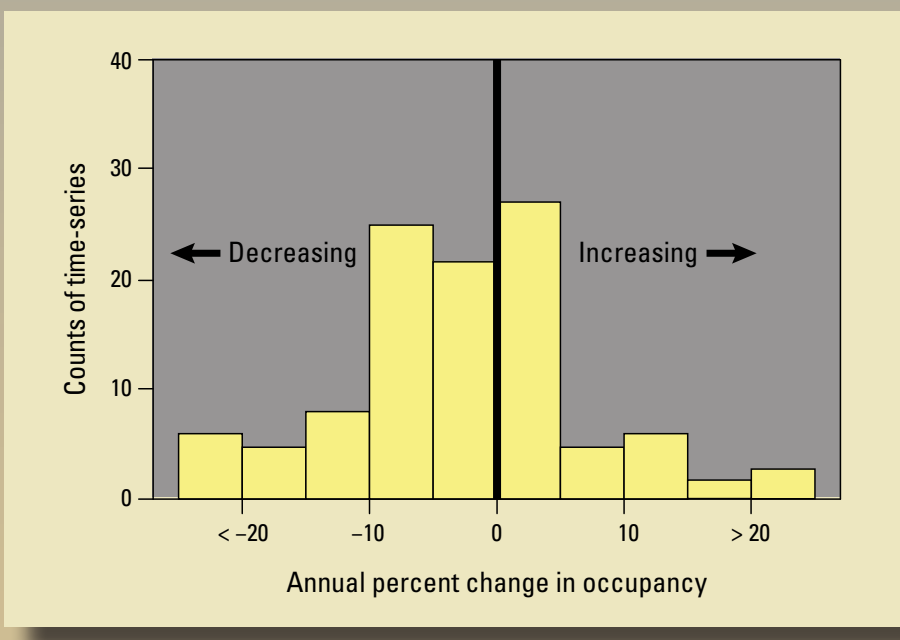

Distribution of trends in the rate of amphibian occupancy for monitoring projects conducted by the U.S. Geological Survey, Amphibian Research and Monitoring Initiative. Each case represents a species by site combination. The mean annual change for all cases was $-3.7 \%$.

These assessments were classified as "expert opinion," which means that they were not necessarily based on quantitative data, but on the field experience and knowledge of professional herpetologists. Although expert opinion surveys should always be interpreted with caution, even the lower of these two estimates suggests a serious problem. The U.S. Geological Survey (USGS) Amphibian Research and Monitoring Initiative (ARMI) maintains a network of monitoring sites where the occurrence and abundance of amphibian populations are estimated statistically to provide the first strictly quantitative assessment of the status of select amphibians across the United States. The ARMI estimate is higher at 61 percent, but includes species exhibiting any level of decline (even a very low level). ARMI estimates a 3.7 percent average annual decline in the proportion of sites occupied by the 50 species that ARMI monitors. This reflects a mean annual change for all cases of $-3.7 \%$, although some cases increased and others decreased much more rapidly than the average. In mathematical terms, this number means that occupancy in any year was equal to the following equation: [(occupancy in the previous year) minus (0.037 times occupancy in the previous year)]. 


\section{The Amphibian Research and Monitoring Initiative}

The USGS established ARMI in 2000 to monitor the status of amphibians and study the causes of decline on public lands in the United States. This was in response to a direct request from the Secretary of the Interior. ARMI scientists estimate abundance or occupancy across a network of amphibian populations at regular intervals and develop research to address hypotheses about the causes of decline. Monitoring is accomplished in partnership with other Department of the Interior agencies and is designed in a way that not only provides information on status, but also informs management decisions. This is possible because ARMI produces statistically unbiased estimates that, over time, can be related to potential causal factors. This program is among the first of its kind to use interdisciplinary tools at broad scales to examine a biological phenomenon.

\section{Why are Amphibians Declining?}

\section{Habitat Destruction and Alteration}

Land-use change is a key reason for the loss of global biodiversity and is the most obvious cause of amphibian declines in the United States. Destroying habitat directly eliminates populations and increases the isolation of remaining populations in a landscape. When the space between habitat patches is hostile, the ability of amphibians to move across the landscape to find food, breed, or recolonize areas decreases. The effects of habitat loss are dramatic but in some ways could be the easiest to manage.

\section{Introduced Species}

Many species of plants and animals around the world are now found in areas outside their natural range. Some of these introduced (or invasive) species cause harm to native species. For example, the introduction of sport fish to formerly fishless habitats is a major concern for amphibians in the western United States (Knapp and Matthews, 2000), and the American Bullfrog is a widely introduced species that, among other things, can act as a vector for disease (Daszak and others, 2004; Schloegel and others, 2010). American Bullfrogs are associated with declines of some native amphibians in the United States (Bury and Whelan, 1984).

\section{Contaminants}

Contamination of the environment can have direct and indirect effects on amphibians. Some contaminants, like acid rain, can kill tadpoles outright, while others such as pesticides, can disrupt hormonal systems and interfere with reproduction (Hayes and others, 2002). Anatomical deformities and behavioral changes related to pollutants lower the life expectancy and breeding potential of amphibians.

\section{Disease}

Emerging infectious diseases, especially rana virus and the amphibian chytrid fungus (Batrachochytrium dendrobatidis, $\mathrm{Bd}$ ) are contributing to amphibian declines (Daszak and others, 1999; Briggs and others, 2005; Gray and others, 2009). Evidence suggests that Bd is a dominant factor in some of the more puzzling amphibian declines around the world and has affected species in the United States. The long-term effects of Bd on amphibian populations in the United States are poorly understood.

\section{The Amphibian Chytrid Fungus (Batrachochytrium dendrobatidis, Bd)}

The amphibian chytrid fungus causes a disease called chytridiomycosis that is lethal to many amphibians. Well-known examples of populationlevel extirpations related to chytrid fungus include those in California (Vredenburg and others, 2005, Central America (Lips and others, 2006), and Australia (Skerratt and others, 2007). The amphibian chytrid fungus appears to be widespread in the United States

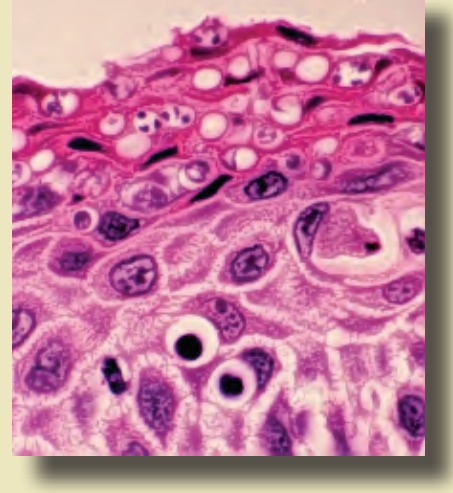

Cross section of amphibian epidermis infected and thickened by the amphibian chytrid fungus, photograph by D.E. Green, U.S. Geological Survey.
(Fellers and others,

2001; Longcore and others, 2007; Rothermel and others, 2008; Muths and others, 2008; Adams and others, 2010; Hossack and others, 2010). The fungus is present in species that are candidates for federal listing, such as the Oregon Spotted Frog, species that are apparently common, such as the Pacific Tree Frog, and in invasive species, such as the American Bullfrog that can act as a reservoir and vector for this disease. Although extirpations have been linked to chytrid fungus infections in the United States, there also is evidence for the persistence of some populations despite the presence of this fungus (Briggs and others, 2005; Grant and others, 2008; Pilliod and others, 2010).

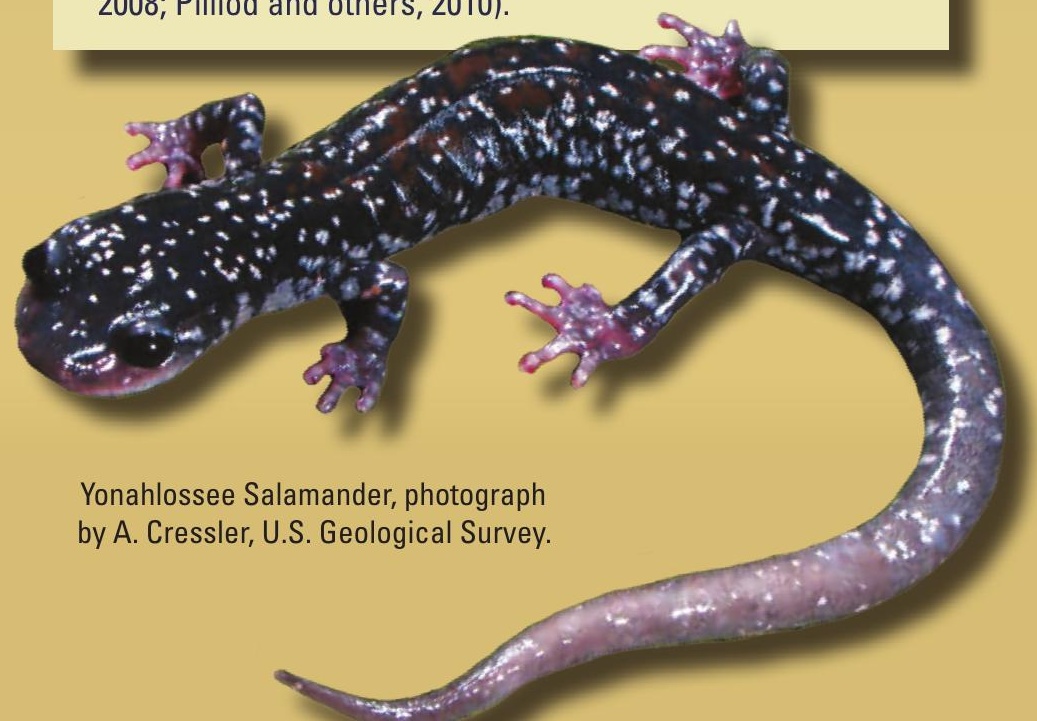




\section{Examples-Classifying Amphibian Problems}

The following examples illustrate the continuum of categories that describe the plight of some amphibians and highlight insights gained from recent research.

Declining-The Mountain Yellow-legged Frog has declined dramatically in the Sierra Nevada of California (Vredenburg and others, 2005). Contributing factors include stocking non-native fish into lakes where the frogs breed (Knapp and Matthews, 2000), disease (Rachowicz and others, 2006), and environmental pollutants (Davidson, 2004).

Insight: Multiple factors may contribute to a particular decline and even "pristine" locations are at risk.

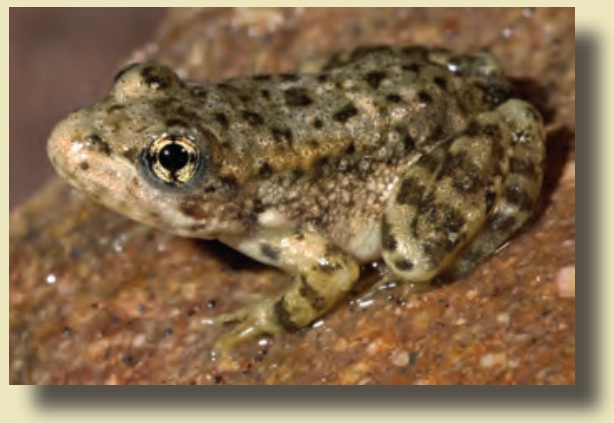

Mountain Yellow-legged Frog, photograph by C.W. Brown, U.S. Geological Survey.

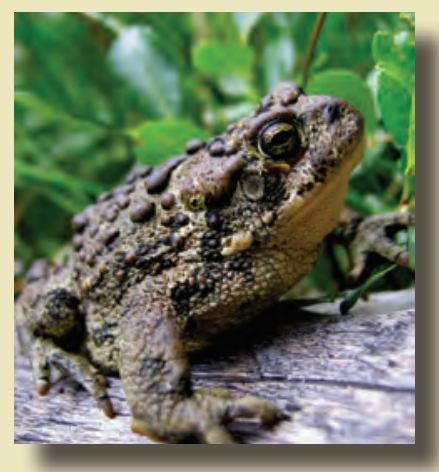

Equivocal - The Boreal Toad is clearly declining in Colorado (Corn and others, 1989), but evidence for decline of the same species in Oregon is less convincing (Wente and others, 2005; Pearl and others, 2009). Declines in this species, at least in the southern Rocky Mountains, appear to be related to disease (Muths and others, 2003; Carey and others, 2005).

\section{Insight: One location does not provide an accurate picture} about a species throughout its range.

Boreal Toad, photograph by

D. Herasimtschuk.

Apparently Robust-The Boreal Chorus Frog occupies a wide variety of habitats in the western United States. Although Boreal Chorus Frogs are susceptible to Bd, preliminary data suggest that the disease does not seriously affect survival and that populations studied in the Front Range of Colorado appear to be relatively robust (Corn and others, 1989). Some species such as the Boreal Chorus Frog may have an advantage in coping with stressors, but still can be vulnerable to decline. Pronouncing a population to be robust is particularly difficult because without long-term data the natural variability in amphibian reproduction and life histories can mask declines.

Insight: Just as it is difficult to say that a species is declining, it is also difficult to determine that a species is robust.

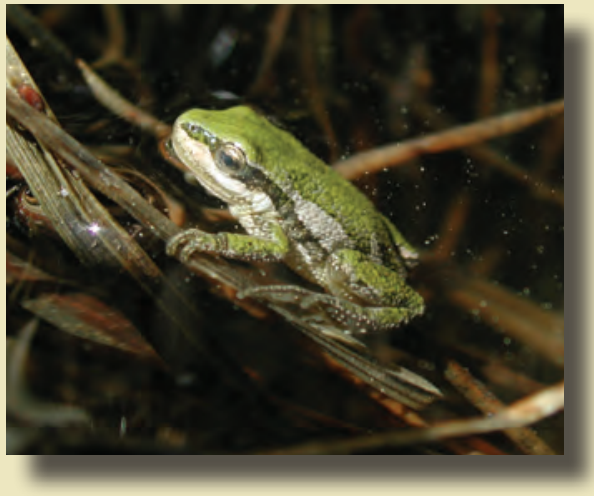

Boreal Chorus Frog, photograph by D. Patla.

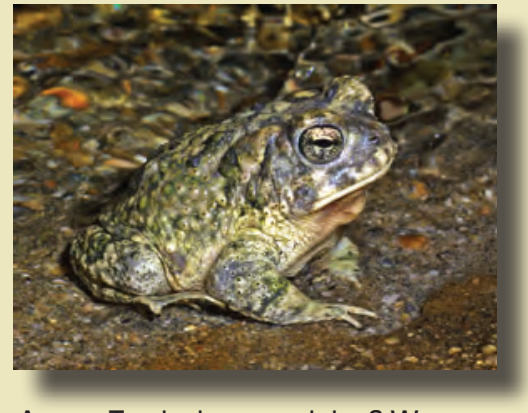

Arroyo Toad, photograph by C.W. Brown, U.S. Geological Survey.
Impacted by Invasives - Invasive fish can curtail breeding in Long-toed Salamanders (Pilliod and others, 2011) and can exacerbate negative interactions between invasive American Bullfrogs and native amphibians (Adams and others, 2003). For example, Chiricahua Leopard Frogs and Arroyo Toads are impacted by American Bullfrogs because this invasive species carries disease and preys on the native species (Daszak and others, 2004).

Insight: Interactions among species can play a role in declines. Negative interactions can be intensified when additional species are introduced. 


\section{Conservation Challenges}

We are faced with the potential disappearance of a significant proportion of an ancient group of vertebrates. Adding to the complexity of amphibian decline, climate change is an overarching process with the potential to interact with any of the identified causes of decline (Lacan and others, 2008; Seimon and others, 2007). Our challenge is to refine our understanding of amphibian declines by pinpointing causes, quantifying observed and suspected declines, and developing appropriate responses, which are the critical steps to conserve the unique amphibian resources of the United States.

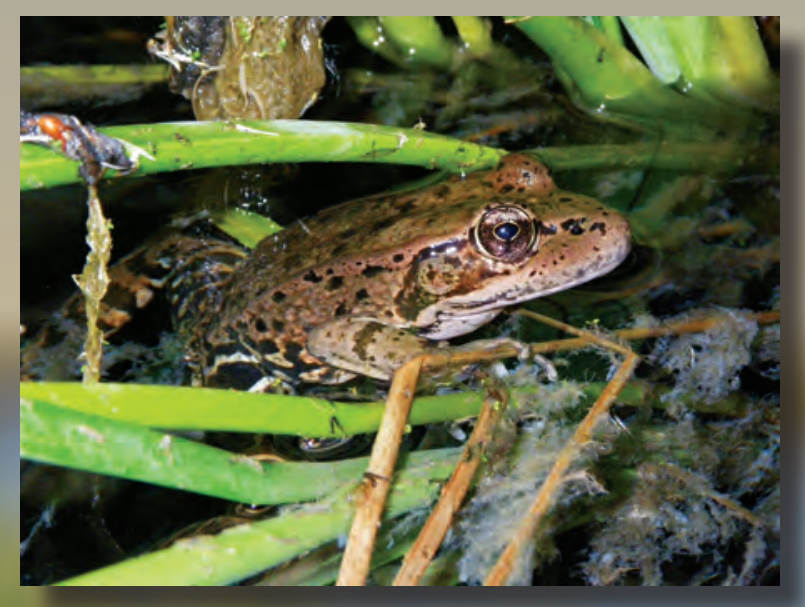

Northern Red-legged Frog, photograph taken by C.W. Brown, U.S. Geological Survey.
Given the limited dispersal ability and specific habitat requirements of most species, developing conservation and management strategies is paramount for ensuring viable populations. Even in protected areas, populations are at risk from past management practices, habitat changes occurring along boundaries, and global threats that affect entire landscapes. ARMI is working with natural resource managers to develop strategies for effective management. This is especially important because many amphibians have restricted or fragmented distributions, which reduces management options. Effective strategies combine our understanding of population trajectories with detailed research into factors that are related to these trends.

\section{ARMI Principles}

- Treat monitoring as research

- Maintain the flexibility to tailor projects to local needs

- Focus on statistically unbiased metrics that can be scaled up to achieve broader synthesis

For ARMI information: http://armi.usgs.gov

\section{For Additional Information Contact:}

National Coordinator, Amphibian Research and Monitoring Initiative U.S. Geological Survey 12201 Sunrise Valley Dr. Reston, VA 20192

This fact sheet including complete literature citations can be found at http://armi.usgs.gov/sota/index.php

This is contribution number 412 of the U.S. Geological Survey Amphibian Research and Monitoring Initiative (ARMI). 